\title{
Species Difference in Metabolism of Strychnine with Liver Microsomes of Mice, Rats, Guinea Pigs, Rabbits and Dogs
}

\author{
Yoko TANIMOTO, Toyomi OHKUMA, Kazuta OGURI, and Hidetoshi YOSHIMURA \\ Faculty of Pharmaceutical Sciences, Kyushu University, Fukuoka, 812, Japan
}

(Received September 8, 1989)

\begin{abstract}
The metabolism of strychnine was studied with hepatic microsomes of rats, mice, guinea pigs, rabbits and dogs, using high-performance liquid chromatography. Eight metabolites were found by the incubation with rabbit liver microsomes. Five of them were identified as strychnine $N$-oxide (St $\mathrm{N}$-oxide), 2-hydroxystrychnine (2-OH St), strychnine 21,22-epoxide, 16-hydroxystrychnine (16-OH $\mathrm{St}$ ) and 18-oxostrychnine by comparing the chromatographic and spectral data to those of authentic samples. Significant differences in metabolic profiles of strychnine were observed among the above species. The main metabolite in rats and mice was $16-\mathrm{OH} \mathrm{St}$, while in guinea pigs and rabbits, and in dogs, it was $2-\mathrm{OH} \mathrm{St}$, and St $\mathrm{N}$-oxide, respectively. The metabolic activity in guinea pig liver microsomes was much higher than those of other species. There seems to be a fairly good inverse correlation between the metabolic activity and strychnine toxicity in guinea pigs and other animal species.

Keywords — strychnine; drug metabolism; species difference; liver microsome; oxidative metabolite
\end{abstract}

\section{Introduction}

Strychnine, an alkaloid of Strychnos nuxvomica, is a competitive antagonist of the neurotransmitter glycine, and in recent years, has been examined for the treatment of nonketotic hyperglycinemia. ${ }^{1)}$ It is also an important drug in the forensic chemical field. The metabolic fate of strychnine has been studied in our laboratory. We, thus, identified five metabolites formed by the incubation with $9000 \times \boldsymbol{g}$ supernatant fraction from rabbit liver ${ }^{2)}$ and six metabolites isolated from urines of rats. ${ }^{3)}$ The studies with $\left[{ }^{3} \mathrm{H}\right]$ strychnine showed its quick metabolism and rapid excretion into the urine and feces in rats. ${ }^{3)}$ However, many metabolites are still unidentified in our previous studies. ${ }^{2,3)}$ Adamson and Fouts ${ }^{4}$ first reported the localization of strychnine metabolizing enzymes in hepatic microsomes. In the present study, we examined the primary metabolism of strychnine with rabbit liver microsomes and quantified the metabolites. In addition, interspecies differences in the in vitro metabolism of strychnine in rats, mice, guinea pigs, rabbits and dogs were studied.

\section{Materials and Methods}

Materials - Strychnine nitrate purchased from Kanto Chemical Co. (Tokyo, Japan) was converted into the hydrochloride and recrystallized from water. Strychnine $N$-oxide (St $N$ oxide), 2-hydroxystrychnine (2-OH St), strychnine 21,22-epoxide (St epoxide), 16-hydroxystrychnine (16-OH St) and 18-oxostrychnine (18-oxo St) were prepared by the method previously reported. ${ }^{2,3)}$ Nicotinamide adenine dinucleotide phosphate (NADP) and glucose-6phosphate (G-6-P) were purchased from Kyowa Hakko Industries Co., Ltd. (Tokyo, Japan) and Oriental Yeast Co., Ltd. (Tokyo, Japan), respectively. G-6-P dehydrogenase (Baker's yeast, type V) was purchased from Sigma Chemical Co. (St. Louis, MO, USA) Other chemicals and solvents used were of the highest quality available commercially.

Preparation of Liver Microsomes - Male New Zealand White rabbits $(3.0-3.5 \mathrm{~kg})$, male Wistar rats $(165-190 \mathrm{~g})$, male ddY mice $(25-30 \mathrm{~g})$ and male Hartley guinea pigs $(300-350 \mathrm{~g})$ were killed after starvation for 22 h. The livers were removed, perfused with physiological saline and homogenized with 3 volumes of $0.25 \mathrm{M}$ sucrose containing $25 \mathrm{mM}$ $\mathrm{KCl}, 5 \mathrm{mM} \mathrm{MgCl}_{2}$ and $50 \mathrm{mM}$ Tris- $\mathrm{HCl}$ buffer (pH 7.5) by using a glass-Teflon homogenizer. The homogenate was centrifuged at $9000 \times \boldsymbol{g}$ for $20 \mathrm{~min}$ and the supernatant was centrifuged 
at $105000 \times \boldsymbol{g}$ for $60 \mathrm{~min}$ to obtain microsomal pellets. These were suspended in $1.15 \% \mathrm{KCl}$ for washing, centrifuged again at $105000 \times \boldsymbol{g}$ for $60 \mathrm{~min}$ and resuspended in the same solution at the protein concentration of $5-13 \mathrm{mg} / \mathrm{ml}$. Male beagle dog livers were kindly donated by Panapharm Laboratories Co. (Kumamoto, Japan), and microsomal suspensions were prepared by the method described above.

Isolation and Purification of Metabolites - Strychnine hydrochloride $(200 \mu \mathrm{mol})$ was incubated with rabbit liver microsomes $(100 \mathrm{mg}$ protein) in a medium consisting of NADP (30 $\mu \mathrm{mol}), \mathrm{G}-6-\mathrm{P}(500 \mu \mathrm{mol}), \mathrm{G}-6-\mathrm{P}$ dehydrogenase (10 units), $\mathrm{MgCl}_{2}(500 \mu \mathrm{mol})$ and Tris- $\mathrm{HCl}$ buffer ( $\mathrm{pH} 8.4,10 \mathrm{mmol}$ ) to make a final volume of $100 \mathrm{ml}$. After preincubation for 2 min at $37^{\circ} \mathrm{C}$, incubation was initiated by addition of strychnine hydrochloride. After incubation for $30 \mathrm{~min}$, the reaction was stopped by addition of $20 \mathrm{ml}$ of $3 \mathrm{~N} \mathrm{HCl}$. The mixture was centrifuged at $3000 \mathrm{rpm}$ for $10 \mathrm{~min}$. The mixture was made alkaline with ammonia and then extracted 3 times with 2 volumes of $\mathrm{CHCl}_{3}$-isopropanol $(3: 1, v / v)$. The extract was applied to preparative thin-layer chromatography (TLC) with a solvent system $\mathrm{A}, \mathrm{CHCl}_{3}$-methanol $(7: 3$, $\mathrm{v} / \mathrm{v})$, and the chromatogram was visualized by ultraviolet (UV) light. Dark bands where metabolites were localized were scraped off giving six portions $(R f 0.15-0.30,0.30-0.52$, $0.52-0.60,0.60-0.71,0.71-0.81$ and $0.81-0.91)$ and extracted with $\mathrm{CHCl}_{3}$-methanol $(1: 1, v / v)$. A mixture of $\mathrm{M}-1, \mathrm{M}-2$ and $\mathrm{M}-3$ ( $R f 0.15-0.30$ ) was further purified with preparative TLC under a solvent system $\mathrm{B}, \mathrm{CHCl}_{3}$ methanol-diethylamine $(15: 1: 4, \mathrm{v} / \mathrm{v})$. A mixture of M-7 and M-8 ( $R f 0.81-0.91)$ was purified with preparative high-performance liquid chromatography (HPLC) carried out under the system I described under Analytical Methods. The eluates on HPLC were made alkaline with ammonia and then extracted with $\mathrm{CHCl}_{3}$-isopropanol $(3: 1, \mathrm{v} / \mathrm{v})$. The metabolites were then identified directly or after converting to trimethylsilyl (TMS) derivatives by gas chromatography-mass spectrometry (GC-MS) under the conditions described in the previous paper. ${ }^{3)}$

Quantitative Determination of Strychnine
Metabolites - Strychnine hydrochloride (1 $\mu \mathrm{mol})$ was incubated with liver microsomes $(0.4 \mathrm{mg}$ protein) in a medium consisting of NADP $(0.3 \mu \mathrm{mol}), \mathrm{G}-6-\mathrm{P}(5 \mu \mathrm{mol}), \mathrm{G}-6-\mathrm{P}$ dehydrogenase (0.2 units), $\mathrm{MgCl}_{2}(5 \mu \mathrm{mol})$ and Tris- $\mathrm{HCl}$ buffer ( $\mathrm{pH} 8.4,100 \mu \mathrm{mol})$ to make a final volume of $1.0 \mathrm{ml}$. After preincubation for 2 $\min$ at $37^{\circ} \mathrm{C}$, the incubation was initiated by addition of strychnine hydrochloride. After 15 $\mathrm{min}$, the reaction was stopped by addition of 3 $\mathrm{ml}$ of ice-cold $0.5 \mathrm{M}$ ammonium sulfate adjusted to $\mathrm{pH} 9.3$ with ammonia. The mixture was applied to Sep-Pak $\mathrm{C}_{18}$ cartridge (Waters Assoc., MA, USA) and washed with $20 \mathrm{ml}$ of $5 \mathrm{~mm}$ ammonium sulfate (pH 9.3) and $0.5 \mathrm{ml}$ of distilled water. Metabolites were eluted with $3.0 \mathrm{ml}$ of $80 \%(\mathrm{v} / \mathrm{v})$ methanol. Recoveries of metabolites ranged from 95 to $100 \%$, whereas that of unchanged strychnine was less than $50 \%$. The eluate was analyzed by HPLC under the conditions of system II described below.

Analytical Methods - HPLC was performed with a Waters $6000 \mathrm{~A}$ pump and an UV detector model $440(254 \mathrm{~nm})$ using two systems, I and II, as follows. Preparative HPLC was performed by use of the system I; the column was $\mu$ Bondapak Phenyl $(6.35 \mathrm{~mm} \times 30 \mathrm{~cm}$, Waters Assoc.), and the mobile phase was acetonitrile-10 mM sodium phosphate buffer $(\mathrm{pH}$ 2.5) $(28: 72, \mathrm{v} / \mathrm{v})$, and the flow rate was 0.8 $\mathrm{ml} / \mathrm{min}$. Determination of the metabolites was conducted by use of the system II; the column was $\mu$ Bondasphere Phenyl $5 \mu-100 \AA(3.9 \mathrm{~mm}$ $\times 15 \mathrm{~cm}$, Waters Assoc.), and the mobile phase was acetonitrile- $10 \mathrm{mM}$ sodium phosphate buffer ( $\mathrm{pH} 2.5$ ) containing $1 \mathrm{mM}$ sodium dodecyl sulfate $(28: 72, \mathrm{v} / \mathrm{v})$, and the flow rate was $0.5 \mathrm{ml} / \mathrm{min}$.

The protein concentration was determined by the method of Lowry et al. ${ }^{5)}$ using bovine serum albumin as the standard.

\section{Result}

\section{Identification of Strychnine Metabolites} Formed with Rabbit Liver Microsomes

As described under Materials and Methods, after extraction of the incubation mixture with $\mathrm{CHCl}_{3}$-isopropanol $(3: 1, \mathrm{v} / \mathrm{v})$, bands of strych- 
TABLE I. Chromatographic and Spectral Data of Strychnine Metabolites by Rabbit Liver Microsomes

\begin{tabular}{|c|c|c|c|c|c|c|c|}
\hline \multirow{2}{*}{ Metabolite } & \multirow{2}{*}{ Compound } & \multicolumn{3}{|c|}{ TLC $R f$ values } & \multirow{2}{*}{$\begin{array}{c}\mathrm{HPLC} \\
t_{\mathrm{R}}(\min )\end{array}$} & \multirow{2}{*}{$\begin{array}{c}\mathrm{GC} \\
t_{\mathrm{R}}(\min )\end{array}$} & \multirow{2}{*}{$\begin{array}{c}\text { Mass spectrum } \\
\left.(m / z)^{a}\right)\end{array}$} \\
\hline & & A & B & $\mathrm{C}$ & & & \\
\hline M-1 & St $N$-oxide & 0.22 & 0.06 & 0.04 & 11.60 & $14.2^{b)}$ & $334\left(\mathrm{M}^{+}, 100\right), 162(11), 130(21)$ \\
\hline M-2 & $2-\mathrm{OH} \mathrm{St}$ & 0.22 & 0.35 & 0.22 & 6.63 & $24.5 c)$ & $422\left(\mathrm{M}^{+}, 100\right)$ \\
\hline M-3 & St epoxide & 0.25 & 0.50 & 0.28 & 7.07 & 17.0 & $350\left(\mathrm{M}^{+}, 100\right), 333(15), 178(52)$ \\
\hline M-4 & & 0.40 & & 0.50 & 9.26 & & \\
\hline M-5 & & 0.67 & & 0.65 & 8.33 & $20.0^{c)}$ & $422\left(\mathrm{M}^{+}, 100\right), 392(98)$ \\
\hline M-6 & & 0.78 & & 0.50 & 10.37 & & \\
\hline \multirow[t]{3}{*}{ M-7 } & $16-\mathrm{OH} \mathrm{St}$ & 0.85 & 0.75 & 0.63 & 9.13 & 12.3 & $332(47), 209(100)$ \\
\hline & & & & & & 14.5 & $332(100)$ \\
\hline & & & & & & 15.3 & $334(100)$ \\
\hline \multirow[t]{2}{*}{ M-8 } & 18-oxo St & 0.85 & 0.80 & 0.67 & 18.30 & 20.4 & $348\left(\mathbf{M}^{+}, 100\right)$ \\
\hline & Strychnine & 0.40 & 0.78 & 0.61 & 9.83 & 14.2 & $334\left(\mathbf{M}^{+}, 100\right)$ \\
\hline
\end{tabular}

Solvent systems in TLC were: $\mathrm{A}, \mathrm{CHCl}_{3}-$ methanol $(7: 3, \mathrm{v} / \mathrm{v}) ; \mathrm{B}, \mathrm{CHCl}_{3}-$ methanol-diethylamine $(15: 1: 4, \mathrm{v} / \mathrm{v}) ; \mathrm{C}, \mathrm{CHCl}_{3}-$ diethylamine $(4: 1, \mathrm{v} / \mathrm{v})$ a) Relative intensities are shown in parentheses. b) Reduced to strychnine with $\mathrm{TiCl}_{3}$. c) TMS derivative.

nine metabolites were divided into six portions on thin-layer plates using the solvent system A, and each band was then examined by HPLC under the system I. Eight peaks (M-1 to M-8) were thus found on HPLC.

Table I summarizes chromatographic and

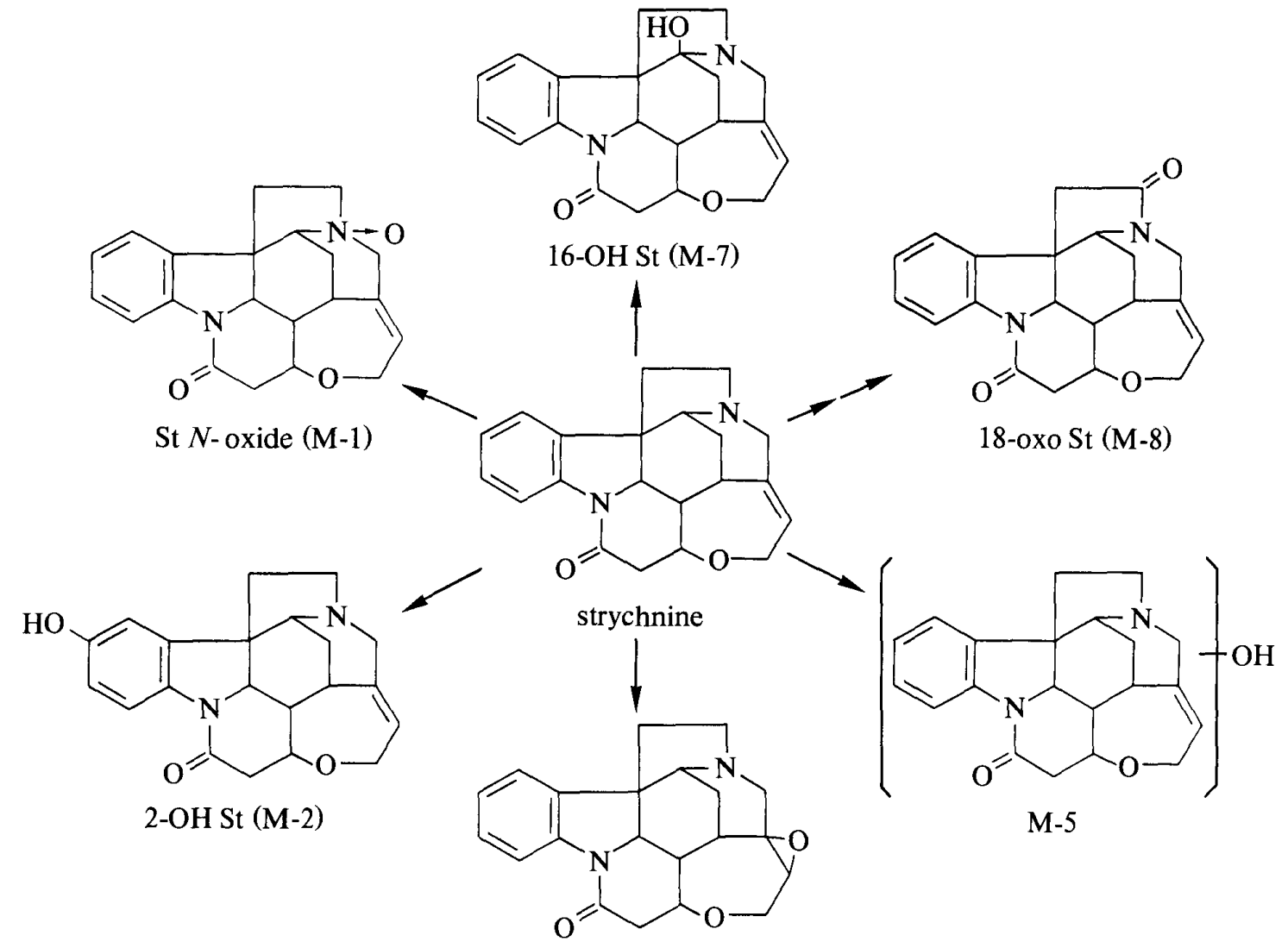

St epoxide (M-3)

Fig. 1. Metabolic Pathways of Strychnine by Rabbit Liver Microsomes 
spectral data of strychnine metabolites formed with rabbit liver microsomes. M-1, M-2, M-3 M-7 and M-8 were identified to be St $N$-oxide, 2-OH St, St epoxide, 16-OH St and 18-oxo St, respectively, by comparison of the retention times $\left(t_{\mathrm{R}}\right)$ on HPLC with those of authentic standards. After further purification by preparative TLC or HPLC, structures of these metabolites were confirmed by GC-MS. M-1 showed a molecular ion peak at $\mathrm{m} / \mathrm{z} 350$ in its direct analysis by electron impact MS, indicating the structure of St $N$-oxide. M-7, labile to GC, was examined by fast atom bombardment MS, showing a $(\mathrm{M}+1)^{+}$ion peak at $\mathrm{m} / z \quad 351$ and a fragment ion peak at $\mathrm{m} / \mathrm{z} 333$. The spectrum supported the structure of $16-\mathrm{OH}$ St.

M-1, M-2 and M-7 were major metabolites, and $\mathrm{M}-3$ and $\mathrm{M}-8$ were minor. M-8 could only be detected by HPLC after purified partially by preparative TLC.

Partially purified M-5, which did not correspond to any authentic samples, was converted to TMS derivative and submitted to GC-MS, which showed a peak at $20.0 \mathrm{~min}$. Its mass spectrum afforded a molecular ion peak at $m / z$ 422, suggesting the presence of a hydroxyl group. However, its structure has not yet been established. Neither M-4 nor M-6 were identified with authentic samples. These minor and unstable metabolites, therefore remain to be identified and quantified.

Thus, in the present study, five strychnine metabolites formed by rabbit liver microsomes were identified with authentic samples. Proposed metabolic pathways of strychnine are shown in Fig. 1.

\section{Species Difference of Strychnine Metabolism}

Metabolites were purified by use of Sep-Pak
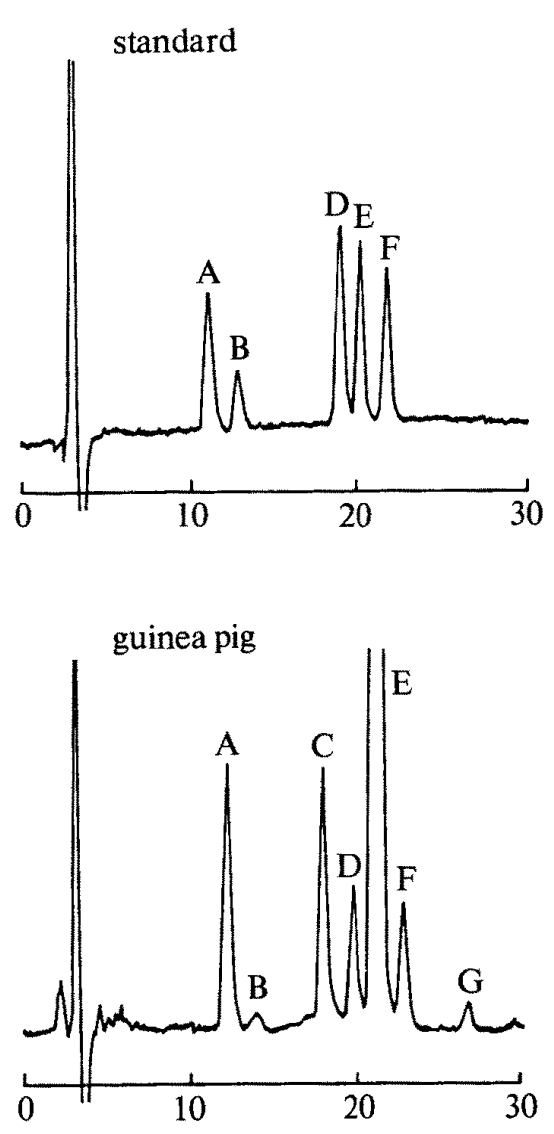
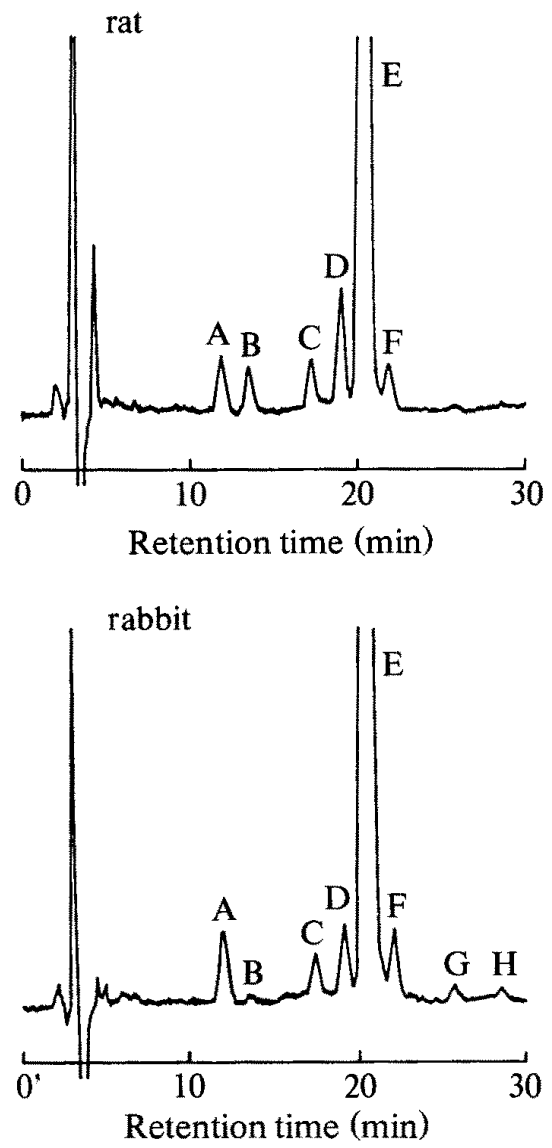
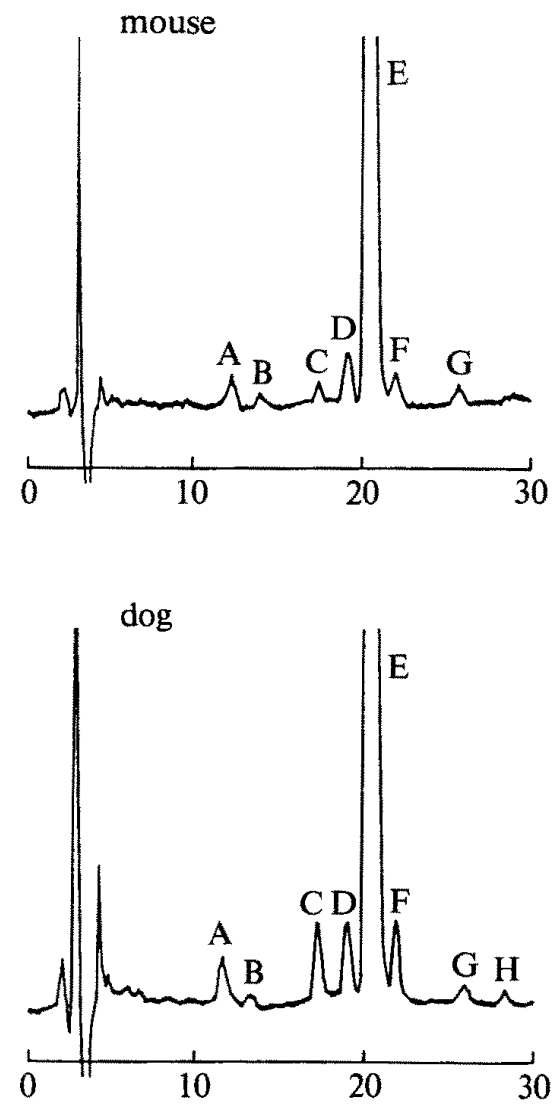

Fig. 2. HPLC Profiles of Strychnine Metabolites Formed by Incubation with Liver Microsomes from Various Animal Species

Liver microsomes $\left(0.4 \mathrm{mg}\right.$ protein) were incubated in the medium described in the text. After applying to Sep-Pak $\mathrm{C}_{18}$ cartridge, $80 \%$ methanol eluates were submitted to HPLC (system II). Peaks: A, 2-OH St; B, St epoxide; C, M-5; D, 16-OH St; E, strychnine; F, St $N$-oxide; G, M-9; H, M-10. 
TÁBLE II. Metabolism of Strychnine by Live Microsomes in Various Animal Species

\begin{tabular}{lccccc}
\hline Metabolite & Rat (4) $a)$ & Mouse (4) & Guinea pig (4) & Rabbit (2) & Dog (2) \\
\hline 2-OH St & $12.3 \pm 1.1$ & $5.91 \pm 0.60$ & $48.7 \pm 2.1$ & 10.8 & 13.1 \\
St epoxide & $6.56 \pm 0.94$ & $1.70 \pm 0.08$ & $1.33 \pm 0.24$ & Trace & 0.37 \\
M-5 & $5.82 \pm 0.61$ & $4.92 \pm 1.45$ & $24.8 \pm 2.3$ & 4.01 & 9.48 \\
16-OH St & $16.7 \pm 2.1$ & $9.89 \pm 1.64$ & $15.9 \pm 0.3$ & 6.64 & 9.92 \\
St $N$-oxide & $7.79 \pm 0.56$ & $6.99 \pm 1.64$ & $20.1 \pm 0.7$ & 8.52 & 18.69 \\
M-9 & Trace & $4.08 \pm 0.92$ & $5.98 \pm 0.27$ & 1.84 & 3.37 \\
M-10 & Trace & Trace & Trace & 1.34 & 1.05 \\
\hline
\end{tabular}

a) Values in parentheses represent number of animals used. formed $\mathrm{nmol} / 15 \mathrm{~min} / \mathrm{mg}$ protein.

$\mathrm{C}_{18}$ cartridges, and the $80 \%$ methanol eluates were analyzed by HPLC under the system II. This system effectively separated the standards; 2-OH St, St epoxide, 16-OH St, strychnine and St $N$-oxide (Fig. 2), and enabled to quantify these metabolites.

Figure 2 shows typical HPLC profiles of strychnine metabolites formed by incubation with liver microsomes from various animal species.

In rats, five peaks of metabolites were observed. 16-OH St was the most abundant metabolite, followed by 2-OH St. Peaks of St $N$ oxide, St epoxide and M-5 were also detected.

In mice, the HPLC profile was similar to that of rats. However, unknown metabolite peak named M-9 was found at $t_{\mathrm{R}} 26 \mathrm{~min}$, which was not detected in rats.

In guinea pigs, the HPLC profile was different from that of above animals, showing remarkable formation of 2-OH St and M-5. All peaks of metabolites in guinea pigs, except that of $\mathrm{St}$ epoxide, were significantly higher than those of other species. A peak of M-9 was also observed in guinea pigs.

In rabbits, the metabolic profile was similar to guinea pigs, however the activities were lower. In addition to M-9, another unknown metabolite peak named M-10 was observed at $t_{\mathrm{R}}$ $29 \mathrm{~min}$. Level of St epoxide was very low in rabbits.

In dogs, St $N$-oxide was the main metabolite, and level of 2-OH St, M-5 and 16-OH St were nearly equal. Unknown metabolite M-9 and M-10 were clearly observed, while St epoxide was a minor.

Table II shows the result of determination of strychnine metabolites in the ve five animals. Unknown metabolites were estimated by calibration with the peak area of St $N$-oxide.

\section{Discussion}

The strychnine molecule has a number of possible sites for oxidation. These are, for example, the aromatic ring, the nitrogen atom of tertiary amine $(\mathrm{N}-19)$, and the $\alpha$-carbon atoms adjacent to $\mathrm{N}-19$, and the double bond between $\mathrm{C}-21$ and $\mathrm{C}-22$. The metabolite of strychnine identified for the first time was 2-OH St, an aromatic ring hydroxylation product, in the early study using rabbit liver slices. ${ }^{6)}$ Recently, we again studied strychnine metabolism and identified four metabolites in the study using rabbit liver $9000 \times \boldsymbol{g}$ supernatant fraction. ${ }^{2)}$ These were St $N$-oxide, St epoxide and $21 \alpha$, $22 \alpha$-dihydroxy-22-hydrostrychnine (diOH St) in addition to 2-OH St. In the present study, $\mathrm{diOH}$ St was not detected, probably because of the stability of St epoxide to enzymatic and chemical hydrolysis. We isolated, instead, two other in vitro metabolites, $16-\mathrm{OH}$ St and 18-oxo St, both of which were oxidative metabolites of $\alpha$-carbons adjacent to $\mathrm{N}-19.16-\mathrm{OH} \mathrm{St}$, one of the main in vitro metabolites, was previously found as a urinary metabolite. ${ }^{3)}$ As a good example of such a carbinolamine formation, one thinks of nicotine which is originally metabolized to unstable 5'-hydroxynicotine by microsomal preparations. This is then dehydrogenated 
rapidly to cotinine with hepatic soluble fractions, or further hydrolyzed to ring-opened amino acid. ") In strychnine metabolism, however, a carbinolamine, 16-OH St is relatively stable, because of its sterically hindered tertiary structure. 18-Oxo St appears to be also formed via unstable 18-hydroxystrychnine.

The species difference in the toxicity of strychnine was already known. Kato et al. reported that in guinea pigs and rats, the in vitro metabolic rates of strychnine were closely related to the toxicity of strychnine. ${ }^{8)}$ The present result confirmed this assumption. The metabolic rate of strychnine is highest in guinea pigs, followed by rats and dogs and lowest in mice and rabbits, while the lethal dose is about $44 \mathrm{mg} / \mathrm{kg}$ for guinea pigs, $10-25 \mathrm{mg} / \mathrm{kg}$ for rats, and $1-5$ $\mathrm{mg} / \mathrm{kg}$ for rabbits and dogs by oral administration. ${ }^{9)}$ These results showed a good inverse correlation between the metabolic rate of strychnine and sensitivity to strychnine toxicity of animal species except for dogs. Differences are also observed in major metabolites among the animal species. For example, 16-OH St was the main metabolite in rats and mice, while in guinea pigs and rabbits, and in dogs, $2-\mathrm{OH} \mathrm{St}$ and $\mathrm{St} N$-oxide were the main metabolites, respectively. The toxicities of $16-\mathrm{OH} \mathrm{St}, 2-\mathrm{OH} \mathrm{St}$ and St $N$-oxide have been reported to be lower than that of strychnine. ${ }^{10,11)}$ The metabolites, therefore, do not appear to contribute to the toxicity of strychnine, but to detoxification.

\section{Acknowledgements}

The authors thanks Miss Setsuko Enjoji for her contributions in this work.

\section{References}

1) R. Gitzelmann, B. Steinmann, A. Otten, G. Dumermuth, M. Herdan, J. C. Reubi, and M. Cuenod: Nonketotic hyperglycinemia treated with strychnine, a glycine receptor antagonist, Helv. Paediatr. Acta, 32, 517-525 (1977).

2) M. Mishima, Y. Tanimoto, K. Oguri, and H. Yoshimura: Metabolism of strychnine in vitro, Drug Metab. Dispos., 13, 716-721 (1985).

3) K. Oguri, Y. Tanimoto, M. Mishima, and H. Yoshimura: Metabolic fate of strychnine in rats, Xenobiotica, 19, 171-178 (1989).

4) R. Adamson and J. R. Fouts: Enzymatic metabolism of strychnine, J. Pharmacol. Exp. Ther., 127, 87-91 (1959).

5) O. H. Lowry, N. J. Rosebrough, A. L. Farr, and R. J. Randall: Protein measurement with the Folin phenol reagent, J. Biol. Chem., 193, 265-275 (1951).

6) H. Tsukamoto, K. Oguri, T. Watabe, and H. Yoshimura: Metabolism of drugs, XLI. The metabolic fate of strychnine in rabbit liver, J. Biochem. (Tokyo), 55, 394-400 (1964).

7) J. W. Gorrod and P. Jenner: The metabolism of tobacco alkaloids, Essays Toxicol., 6, 35-78 (1975).

8) R. Kato, P. Vassanelli, and G. Frontino: Metabolic factors determining a higher resistance to strychnine in guinea pigs, Arch. Int. Pharmacodyn. Ther., 144, 416-422 (1963).

9) Y. Ikeda: "Yakubutsu Chishiryo Shu," 8th ed., Nanzando, Tokyo, 1953, pp. 103-104.

10) F. Sandberg and K. Kristianson: A comparative study of the convulsant effects of Strychnos alkaloids, Acta Pharm. Suec., 7, 329-336 (1970).

11) L. Bohlin, Y. Ali, and G. M. Iskander: Synthesis and convulsant effects of 2- and 3-substituted strychnine derivatives, Acta pharm. Suec., 12, 461-466 (1975). 